\title{
ASSESSING TRAINING NEEDS OF TRANSITION SERVICES FOR TEACHERS OF LEARNING DISABLED STUDENTS IN THE SECONDARY STAGE IN SAUDI ARABIA
}

\author{
MunirahAL-Hudaib, Nadia Tazi and Saeed Al-Yamani \\ Arabian Gulf University, Bahrain
}

\begin{abstract}
This study aimed to identify training needs of transitional services for teachers of secondary learning-disabled girls in Saudi Arabia, and determine the differences in training needs of transition services for teachers pursuant to the variables: educational level, years of experience, and training courses. A descriptive method was used here, specifically developed to measure these needs. The sample represented all secondary schools providing learning disabilities programs in Saudi Arabia. Participants included 39 female teachers of learning disabilities during the school year 2015-2016. Results indicated that teachers of learning-disabled girls lack knowledge and skills to effectively provide transition services, and need training and qualification in some areas. The most important areas needing training and their percentagesare Interagency Collaboration (90.91\%), Career Development(77.78\%), Transition Planning(50\%), Leadership \&Policy(40\%), Secondary Academic Programs (33.33\%), Family Collaboration (20.00\%), and Assessment (11.11\%). Findings showed that teachers no need training courses in Community-Referenced Curriculum \&Programs . Concerning variables, statistically significant differences existed at the level of training needs for teachers regarding transition services $(0.05 \%)$. Teachers' educational level and years of experience had no significant effect on teachers' knowledge and skills for transition services. Results are discussed and some recommendations are suggested.
\end{abstract}

Keywords: Training, Needs, Transition, Services

\section{Introduction}

Teaching students with learning disabilities (LD)is designed to meet the unique needs of each learner, aimed to help raise the level of academic achievement, including performance in all academic subjects and materials, and other aspects such as social and behavioral areas, development of motivation, and assistance in overcoming difficulties.

Since learning disabilities is a continued process, there are some groups of learning-disabled students (adolescents with LD) who need additional special services -in essence transitional services (Al-Hadidy\& al-Khatib, 2005).

Transition for students with special needs, from school borders to post-secondary stages, represents a big problem for them in that they often face great difficultiesthat they cannot overcomein the absence of transitional services and support for such a group of students (Al-Battal, 2011). It is observed that many students with special needs, including those with LD, drop out from school or exceed school age and still lack in academic and social skills to qualify them to obtain and retainemployment(Al-Qaruty, 2005). Consequently, there is a vital need to find effective, organized transitional programs in proper order to guide these students and others, and to provide them with direction to proceed from secondary school into postsecondary education or practical life. For this reason, this type of service has become the cornerstone of successful special needs programs. 


\section{Research Problem}

The Individuals with Learning Disabilities Education Act (IDEA) in the United States of America (1997, 2004) states that teachers of girls with learning disabilities should possess necessary skills and knowledge to provide girls with $\mathrm{LD}$ with teaching that can help them transit into external life, adapt successfully, and pursue specific careers or lines of work (Dinglem,Falvey, Givner\&Haager, 2004).

The American National Joint Committee on Learning Disabilities argues that many learning-disabled female students are unaware or ignorant of the fact that there are options and alternatives after secondary education, due to a failureon the part of their teachers to inform, encourage, support, assist, or prepare them for the future. This has prompted the committee to consider the necessity of training able teachers to teach students with LD how to choose an alternative postsecondary education, as well as of how to design and implement an effective transitional plan suitable to each girl and her own special needs (Levinson \& Palmer, 2005).

Developing a transitional plan and providing its services is critical to help and assist girls with LD, provided that this plan is extensive and includes several aspects and areas such as teaching, employment, personal responsibility, relationships, family, and others (National Joint Committee on Learning Disabilities, 1994). Beard (1991) noted that there are some female teachers of learning-disabled student who offer these services to girls although they are not well-trained in providing transitional services, which is a continued challenge facing all teachers today (Blalock, et al., 2003).It has become an urgent necessity to offer students transitional services by highly qualified and trained teachers to enable LD students toconfront and overcome their challenges. It is thus critical for teacher education programs to assure the competences of teachers to enable them to provide effective transitional services (Morgan, Callow-Heusser, Horrocks, Hoffmann, Kupferman, 2014).

There is an important role to be played byteachers to improve the effectiveness of transitional teaching. IDEA argues that there are important instructions concerning teachers' qualification and competencies. For teachers to be qualified in teaching in the transitional process, they should possess sufficient skills and knowledge to provide transitional services in an effective manner (Morningstar, \& Clark, 2003). Through the researcher's field experience working with schools, it is clear that there is a defect in the transitional processes from secondary schools to postsecondary stages, and that these services have not been given due care or attention. In accord, it should be crucial to find organized, effective transitional programs to guide these girls. Yali, Bassett, and Hutchinon (2009) noted the vital role played by inservice training to raise the level of learning-disabled girls' teachers in transitional processes, as compared to pre-service training, underlining that female teachers' training in the transitional field has become an urgent and desired issue. Thus informed, the research problem of this study is to assess the training needs associated with transitional services for female teachers of girls with LD at the secondary stage in Saudi Arabia.

\section{Research Questions}

This study attempts to answer the following questions:

1. What are the training needs in transitional services for female teachers of the learning-disabled girls in Saudi Arabia?

2. Are there differences in training needs to transitional services for female teachers of the learning-disabled girls in Saudi Arabia according to these variables: years of experience, qualification, and number of training courses in the field of transitional services?

\section{Purposes}

The purpose of this study is:

1. To identify the training needs in transitional services for female teachers of learning-disabled 
girls in Saudi Arabia, and

2. To investigate differences in training needs of transitional services for female teachers of learning-disabled girls in Saudi Arabia pursuant to these variables: years of experience, degree ofqualification, and number of training courses in the field of transitional services.

\section{Significance of Research}

The significance of this study lies in two aspects: scientific importance and applicability.

\section{First, Scientific Importance}

This scientific importance lies in the scarcity of research and studies on training needs in transitional services in general in the Arab world. To the researcher's knowledge, this is the first study in the Arab world to examine the training needs in the field of transitional services for female teachers providing education to girls with LD in Saudi secondary schools.

\section{Second, Importance of Applicability}

To identify the training needs in the field of transitional services for female teachers providing education to girls with LD in Saudi secondary schools may help professionals and personnel in decision-making to improve the quality of these transitional services in a realistic and feasible manner so that girls with LD can transit to postsecondary easily. Moreover, this can be an addition to the Arab library by providing a framework about transitional services for Saudi students with LD.

\section{Limits}

Spatial: This study was limited to all secondary schools providing LD programs in four Saudi areas: Riyadh, Majmaa, Jeddah, and Mecca.

Chronological: Training needs-related data were collected in the school year 2015-2016.

\section{Method}

A descriptive method (survey) was used here as it was suitable to the research aim.

Population: The study population consisted of all female teachers of learning-disabled girls in Saudi secondary schools during the school year 2015-2016.

\section{Participants}

The sample consisted of female teachers working with girls with LD in Saudi girls' secondary schools in the school year 2015-2016. For the shortage of LD teachers in Saudi Arabia a comprehensive sample was used here (39 teachers).

\section{Instrumentation}

A tool was developed specifically for this study based on the Likert-4 point scale to identify the training needs in the field of transitional services for female teachers providing education to girls with LD in Saudi secondary schools through a review of literature on the topic of skills and knowledge required by female teachers in secondary schools to provide effective transitional services to students with LD. Additionally, some Arab and foreign testing, measures, and surveys concerning teachers' competences in the field of transitional services to girls with LD were reviewed. The final tool had 69 items regarding skills that should be available to provide transitional services. The scale items were divided into eight dimensions with each including transitional planning, assessment, and family collaboration.

\section{Results}

The findings related to Question One: "What are the training needs in transitional services for female teachers of learning-disabled girls in Saudi Arabia?" 
Munirah AL-Hudaib, Nadia Tazi and Saeed Al-Yamani/Assessing Training Needs of Transition Services for Teachers of Learning Disabled Students in the Secondary Stage in Saudi Arabia

Table 1 Sample's Needs Concerning Service Areas

\begin{tabular}{lcccc}
\hline \multicolumn{1}{c}{ Field } & Mean & SD & Trend \\
\hline Community-Referenced & & & \\
Curriculum \& Programs2.880.84 Qualified & & \\
Assessment & 2.700 .77 Qualified & \\
Family Collaboration & 2.59 & 0.75 & Qualified & \\
Secondary Academic Programs & 2.59 & 0.78 & Qualified \\
Leadership \&Policy2.58 & 0.81 & Qualified & \\
Transition Planning & 2.57 & 0.72 & Qualified & \\
Career Development 2.41 & 0.78 & Not qualified \\
Interagency Collaboration & 2.33 & 0.78 & Not Qualified \\
Total Score & 2.64 & 0.88 & Qualified
\end{tabular}

Figure 1 Areas that should be effectively available for transitional services for LD

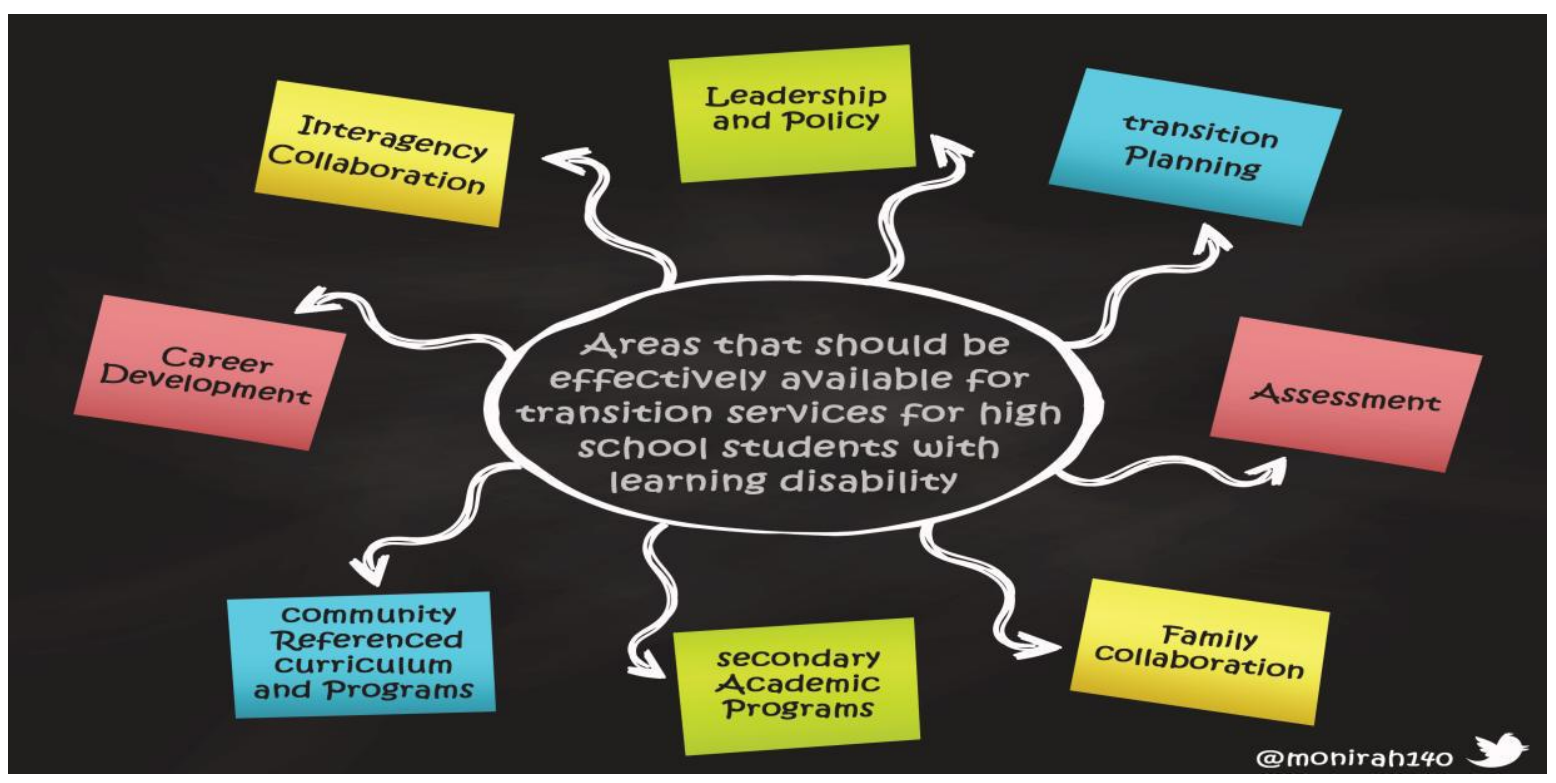

A set of results were drawn:

- At the level of the eight dimensions of the transitional services areas, training needs can be divided into two main sections: (a) no need to training programs, and (b) a need to training programs. Generally, the female teachers of the girls with LD need training in the field of professional development and in civil society organization cooperation.

- These teachers do need training in the field of community-referenced programs and curricula.

As seen in table 1 and Figure 1, each mean over 2.50 is considered qualified, whereas a mean less than 2.50 is considered not qualified. 
The following is a detailed analysis of teacher responses to skills items in each field:

- Teachers need to training in assessment:

- Determining relevant jobs based on the assessment findings in terms of girls with LD's interests, abilities and tendencies.

- Teachers need training in family collaboration:

- $\quad$ Training parents in transitional services-related issues

- Communication with various cultural organizations to assure the participation of a large number of learning-disabled girls' families.

- Teachers need training in secondary academic programs:

- Providing classroom teachers with information about transitional services with an aim to include them in public academic curricula.

- $\quad$ Adapting transitional services to models used in the Ministry of Education.

Concerning other areas, we focus on the most important items:

- Teachers need training in politics and leadership:

- $\quad$ Adapting transitional services programs for the with LD as required.

- Using research results in developing transitional service programs for girls with LD.

- Teachers need training in transitional planning:

- An individual plan should meet and achieve the transitional services goals related to education, employment and independent skills for postsecondary girls.

- To involve the families of girls with LD in planning transitional services, coordinating a meeting plan for transitional services with stakeholders (college special needs center-institutescraftsmen).

- To determine labor market needs for postsecondary stage and coordination with relevant communities and organizations.

- Teachers need training in professional development of a high caliber:

- To supply typically developmental girls' female teachers with information to help girls with LD choose their career and realize its requirements.

- To provide normal classrooms teachers with information concerning career-related behaviours and skills (job application, work behaviours) and a high-quality level of training.

- $\quad$ To assist girls with LD through modifying learning settings to suit to their abilities.

- To provide a database of available job opportunities for girls with LD in the field of work, study, internal training, co-operation with authorities related to the labor market and their needs for employment.

- Teachers need training in the field of civil inter-institutional cooperation:

- To providecomprehensive informationfor all such assupporting and assistive services from civil societal organizations to girls with LD, and helpingthe girls with LD to receive services offered by the civil society organizations.

- To know the role played by civil society organizations and their subsystems in the field of transitional services.

- $\quad$ To make school-civil society organization treaties.

- To find solutions with civil society organizations and relevant authorities to overcome obstacles that hinder provisionof transitional services to girls with LD.

Results concerning research question two: "Are there differences in training needs to transitional services for female teachers of the learning-disabled girls in Saudi Arabia according to these variables: years of experience, qualification, and number of training courses in the field of transitional services?"

- There are no statistically significant differences in the female teachers' needs for training that can be attributed to difference in number of years of experience.

- There are no statistically significant differences in the female teachers' needs for training attributable to difference in qualifications. 
- There are statistically significant differences in the female teachers' needs for training in transitional services and participation in training courses.

\section{Recommendations}

The following recommendations are based on the study findings:

- It is crucial to devise new and specialized regulations and legislation in regard to transitional services, with oversight toensure effective implementation by all parties interested in transitional services.

- It is critical to find an academic curriculum for transitional services at Saudi universities for special needs personnel in their final year that focuses on professional development and cooperation among civil society institutions.

- Girls with LD should be supervised and observed to monitor and ensure their qualitative level of transitional services provision at the secondary level.

- It is vital for the public and private sectors to cooperate with the Ministry of Education to facilitate transitional services provision by qualifying the secondary girls' professional status.

- Offering workshops and training courses for female teachers of girls with LD and teachers in general education to develop their aptitude in postsecondary transitional services provision, and to improve their qualitative level of training.

- It is important for Saudi universities to cooperate with Ministry of Education to offer suitable opportunities for girls with LD through a college special needs center.

- It is necessary for families of girls with LD to collaborate with transitional team members, to participate in transitional planning, to understand all of their rights as children, and to provide all necessary support and assistance.

- To conduct more research in this field so that all interested parties can offer services in an improved manner and to overcome any and all obstacles that result.

\section{Suggested Future Research}

\section{It is recommended to conduct future research to deal with the following topics:}

- The effectiveness of a training course for female teachers of girls with LD to provide postsecondary transitional services.

- The effect of transitional services on the future of the girls with LD.

- Providing transitional services programs for the secondary girls with LD from the perspective of female teachers and the girls' families.

- The differences in transitional services programs among groups of individuals with special needs in Saudi Arabia.

\section{References}

Al-Battal, Z.B.M. (2008). Transitional Needs for the Disabled Individuals. Al-Manal Journal,Sharjah City for Human Services, 222, pp. 24-25.

Al-Battal, Z.B.M. (2011). Academic Considerations for College Disabled Students. Master Thesis at King Saud University, Riyadh, Saudi Arabia.

Al-Hadidi, M; \& Al-Khateeb, J. (2005). Teaching Strategies for Special Needs students. Amman, Dar AlFikr.

Al-Qaruti, Y. (2005). Transitional Services: The Arab Special Needs Conference: Reality and Desires. Jordan, Amman, Reviewed10/1/2016 on http://cutt.us/wPqzg 
Beard, J. (1991). State directors of special education transition programs: StateDefinitions and real and ideal teacher competencies. Available from ERIC Document Reproduction Service ( No. ED 342543).

Blalock, G., Kochhar-Bryant, C. A., Test, D. W., Kohler, P., White, W Lehmann,J.,\& Patton, J. (2003). The need for comprehensive personnel preparation in transition and career development: A position statement of the division on career development and transition, fromhttp://cde.sagepub.com/content/26/2/207.

Dinglem, M., Falvey, M. A., Givner, C. \&Haager, D. (2004). Essential special and general education teacher competencies for preparing teachers for inclusive settings. Issues in Teacher Education, 13(1), 35-50.

Levinson, E. M., \& Palmer, E. J. (2005). Preparing students with disabilities for school-to-work transition and post school life.Counseling 101, 11-15, provided by the National Association of School Psychologists (www.nasponline.org)

Morgan, R. L., Callow-Heusser, C. A., Horrocks, E. L., Hoffmann, A. N.,\&Kupferman, S. (2014). Identifying transition teacher competencies through literature review and surveys of experts and practitioners. Career Development and Transition for Exceptional Individuals, 37(3), 149-160.

Morningstar, M. E., \& Clark, G. M. (2003). The status of personnel preparation for transition education and services: What is the critical content? How can it be offered?.Career Development for Exceptional Individuals, 26(2), 227-237.

National Joint Committee on Learning Disabilities. (1994). Secondary topostsecondary education transition planning for students with learning disabilities. Retrieved fromhttp://www.asha.org/policy/RP1994-00133

Yali, J., Bassett, D. S., \&Hutchinon, S.R. (2009) . Secondary special educators'transition involvement. Journal of IntellectualDevelopmental Disabilities, 34(2), 163-172. 